\title{
Patent Term Adjustment: Recent Developments at the Federal Circuit and PTO
}

\author{
By CHRISTOPHER M. HOLMAN
}

$\mathrm{C}$ ONgRess amended the U.S. Patent Act in 1999 to provide for an adjustment to the patent term designed to compensate the patentee for delays in the examination and issuance of the patent that are attributable to the Patent and Trademark Office (PTO). Patent term adjustment (PTA) can be particularly important for pharmaceutical patents, given the tremendous revenue successful brand drugs can generate so long as they can block generic competition. Not surprisingly, most of the important Federal Circuit decisions interpreting the Patent Act's PTA provisions have arisen out of disputes between pharmaceutical companies and the PTO regarding that agency's interpretation and application of those provisions. For a blockbuster drug, even a few days of additional patent term can be worth fighting for. ${ }^{1}$

One of the more significant of these disputes resulted in the Federal Circuit's 2019 decision in Supernus Pharm., Inc. v. Iancu, in which the court held that the PTO's interpretation of 35 U.S.C. $\S 154(\mathrm{~b})$, the section of the Patent Act that provides for and governs PTA, was inconsistent with the plain language of the statute, and had resulted in the patentee pharmaceutical company being shortchanged 646 days of patent term. ${ }^{2}$ On June 16, 2020, in response to Supernus, the PTO published its final rule revising the regulations pertaining to PTA so as to bring them into compliance with the

Christopher M. Holman is a Professor of Law at the University of Missouri-Kansas City School of Law; a Senior Scholar at the Center for the Protection of Intellectual Property at the Antonin Scalia Law School, George Mason University; and the Executive Editor of Biotechnology Law Report.
Federal Circuit's decision. This Report begins with an overview of $\S 154(\mathrm{~b})$, followed by a review some important Federal Circuit decisions that have addressed its interpretation, many of which, like Supernus, have held that the PTO had misinterpreted and/or misapplied $\S 154(\mathrm{~b})$ to the detriment of patent holders, thus requiring that the PTO modify its practices. The Report also summarizes the PTO's most recent revisions to its regulations and practices as a result of the Supernus decision, before concluding with some thoughts on the takeaway for patent practitioners.

\section{U.S.C. $§ 154(b)$}

As explained by the Federal Circuit in Supernus:

Prior to June 8, 1995, the term of a patent was seventeen years, measured from the date that the patent issued to its expiration date seventeen years later.... When the United States entered the World Trade Organization, it assumed certain obligations and commitments under the terms of the World Trade Organization Agreement on Trade Related Aspects of Intellectual Property Rights. As a result, Congress changed the patent term from seventeen years to twenty

\footnotetext{
${ }^{1}$ See, e.g., Actelion Pharm., Ltd. v. Matal, 881 F.3d 1339 (Fed. Cir. 2018) (Patent and Trademark Office (PTO) granted 40 days of patent term adjustment (PTA) for patent claiming pharmaceutically active compounds, and patentee sued the PTO contending that the patent was entitled to 45 PTA days, or alternatively, at least 41 PTA days).

${ }^{2}$ Supernus Pharm., Inc. v. Iancu, 913 F.3d 1351 (Fed. Cir.
} 2019). 
years, measured from the filing date of the earliest United States non-provisional application for the patent.

In addition to extending the patent term from seventeen years to twenty years, Congress passed the patent term adjustment ("PTA") statute in 1999 in an effort to discourage delay in the patent application process (codified at 35 U.S.C. § 154(b)). Specifically, § 154(b) grants the [PTO] authority to adjust the patent term by adding days to account for delays caused by the USPTO. Such adjustments are favorable to an applicant because they extend the life of the patent. But the USPTO may also reduce the PTA in order to account for delays caused by the applicant. ${ }^{3}$

The provisions of $\S 154(\mathrm{~b})$ are fairly complex, but can be summarized as follows. Section 154(b)(1) provides for adjustments to compensate for three types of delay caused by the PTO, often referred to as Type A, $\mathrm{B}$, and $\mathrm{C}$ delays. ${ }^{4} \mathrm{~A}$ Type $\mathrm{A}$ delay occurs when the PTO fails to respond to a patent applicant's submission in a timely manner.

In particular, Type A delay occurs when the PTO fails to:

provide a notification under 35 U.S.C. $§ 132$ or a notice of allowance within fourteen months of an application's filing;

respond to a reply under section 132 , or to an appeal taken under section 134, within 4 months after the date on which the reply was filed or the appeal was taken;

act on an application within 4 months after the date of a decision by the Patent Trial and Appeal Board under section 134 or 135 or a decision by a Federal court under section 141, 145, or 146 in a case in which allowable claims remain in the application; or

issue a patent within 4 months after the date on which the issue fee was paid under section 151 and all outstanding requirements were satisfied. ${ }^{5}$

Common examples of Type A delay would be a failure of the PTO to issue a first action to a patent application within 14 months of its filing date, such as with a restriction requirement or office action, or to fail to respond to a patent applicant's reply to an office action within four months. The statute provides that "the term of the patent shall be extended 1 day for each day" the USPTO does not meet its response deadlines.
Type B delay occurs when the PTO fails to issue a patent within three years of the filing date. Under the statute, any time "consumed" by an applicant's request for continued examination (RCE), derivation proceeding, interference proceeding, secrecy orders, or by appeals to the Patent Trial and Appeal Board (PTAB) or the Court of Appeals of the Federal Circuit, does not count toward the three years allotted to the PTO. ${ }^{6}$ Furthermore, processing delays requested by the applicant do not count toward the allotted three years. The patent term is extended by one day for each day of Type B delay.

Finally, Type $\mathrm{C}$ adjustments are for delays that are excluded from the Type $\mathrm{B}$ delay due to derivation proceedings, interference proceedings, secrecy orders, or successful appeals. ${ }^{7}$ For example, time spent in any derivation or interference proceeding is excluded from the calculation of Type B delay, but restored as Type $\mathrm{C}$ delay. Thus, if it took six years for a patent to issue, but the application was involved in an interference proceeding for two of those years, Type B delay would be one year, i.e., six years minus the three years allotted under the statute minus the two years taken up by the patent interference proceeding. Type $\mathrm{C}$ delay would be two years. The total patent term adjustment for Type $\mathrm{B}$ and $\mathrm{C}$ delay would be three years (there might also be PTA for Type A delay if that occurred). Note that the time consumed by an unsuccessful appeal does not constitute Type C delay; a patent applicant will only be compensated for time consumed pursuing a successful appeal.

Section 154(b) recognizes that conduct by the applicant may also cause delay in patent prosecution, and authorizes the PTO to reduce the total amount of PTA for Type A, B, and C delays by deducting the number of days equal to the period of time that "the applicant failed to engage in reasonable efforts to conclude prosecution of the application." " An applicant is deemed to have failed to engage in reasonable efforts for the cumulative time in excess of three months that the applicant takes to respond to a notice of rejection, objection, argument, or other request from the USPTO. ${ }^{9}$ The statute

\footnotetext{
${ }^{3} I d$. at $1352-53$ (citations omitted).

${ }^{4}$ Some decisions use the terminology A Delay, B Delay, and $\mathrm{C}$ Delay. The A, B, and C refer to the subsections of $\S 154(b)(1)$ which define these types of delay and provide for adjustment to compensate the patentee for them.

${ }^{5} \$ 154(\mathrm{~b})(1)(\mathrm{A})$.

${ }^{6} \$ 154(\mathrm{~b})(1)(\mathrm{B})$.

${ }^{7} \$ 154(\mathrm{~b})(1)(\mathrm{C})$.

${ }^{8} \S 154(\mathrm{~b})(2)(\mathrm{C})(\mathrm{i})$.

${ }^{9} \S 154(\mathrm{~b})(2)(\mathrm{C})(\mathrm{ii})$.
} 
provides that the PTO "shall prescribe regulations establishing the circumstances that constitute a failure of an applicant to engage in reasonable efforts to conclude processing or examination of an application." 10

The statute provides that " $[\mathrm{t}] \mathrm{o}$ the extent that periods of [Type A, B, and/or C delay] overlap, the period of any adjustment granted under this subsection shall not exceed the actual number of days the issuance of the patent was delayed." The meaning of this term was the subject of an important Federal Circuit decision, Wyeth v. Kappos, discussed below.

Section 154(b)(3) of the statute directs the PTO to "prescribe regulations establishing procedures for the application for and determination of patent term adjustments under this subsection," which appears at 37 C.F.R. § 1.701-705. The following decisions address these regulation and the PTO's implementation of $\S 154(b)$.

\section{FEDERAL CIRCUIT DECISIONS INTERPRETING $§ 154(b)$}

Wyeth v. Kappos

In Wyeth v. Kappos, ${ }^{11}$ the Federal Circuit was tasked with interpreting the following provision of $\S 154(b)$ :

To the extent that periods of [Type A, B, and/ or $\mathrm{C}$ delay] overlap, the period of any adjustment granted under this subsection shall not exceed the actual number of days the issuance of the patent was delayed. ${ }^{12}$

The case dealt in particular with the extent to which Type A and B delay "overlaps" under the statute, in which case the two types of delay will not be double counted. The PTO interpreted the statute such that any Type A delay that occurred during the pendency of the patent application "overlapped" with Type B delay, and thus had to be deducted from any Type B delay in calculating the net PTA.

For example, if a patent entitled to twenty days of A adjustments issues twenty days after the three year mark, then it is only entitled to a total of twenty days of adjustment. In other words, the entire period of A delay "overlaps" with the entire period of B delay. Using this framework, the PTO use[d] either the greater of the A delay or B delay to determine the appropriate adjustment but never combine[d] the two. ${ }^{3}$

The Federal Circuit sided with the patentee Wyeth, however, and held that the PTO's interpreta- tion was inconsistent with the plain language of the statute. The court pointed out that, under the statute, the PTO is authorized to promulgate procedures for determining PTA, but not to alter the substance of what Congress set forth in the statute. Under a plain reading of the statute, Type B delay only begins three years after the filing date (or in some cases later, if one of the events set forth in the statute, such as the filing of an RCE, a derivation proceeding, or an appeal occurs). The court explained that, under the statute, Type A delay only overlaps with Type B delay during the period of time in which Type B delay is actually occurring. Type A delay that occurs prior to any Type B delay, i.e., during the three years after the filing date, is not overlapping and counts toward PTA.

To illustrate, consider a case in which, prior to the three-year anniversary of the filing date, there were 30 days of Type A delay attributable to the PTO, and the patent issued 30 days after the three-year deadline, resulting in 30 days of Type B delay. Under the PTO's flawed interpretation of the statute, the two 30-day periods of delay "overlap," and the patentee would only be awarded 30 days of PTA. In contrast, under the correct interpretation of the statute set forth in Wyeth, the Type A delay does not overlap with the Type B delay because it occurred prior to the three-year deadline, and thus prior to the time in which Type B delay began accruing. Since they do not overlap, the Type A delay is not deducted from the total PTA, i.e., a net 60 days.

The difference can be significant. For example, in Wyeth the drug company was appealing the PTA for two patents claiming "inventions to treat Alzheimer's disease." Under the PTO's erroneous interpretation of the statute, PTA for the two patents was calculated to be 462 and 492 days, respectively. Under the correct interpretation of the statute, PTA for the two patents was 756 and 722 days, differences of 304 and 230 days, significant periods of time for an important pharmaceutical patent.

\section{Novartis AG v. Lee}

In Novartis AGv. Lee, a pharmaceutical patentee unsuccessfully challenged the PTO's interpretation of 35 U.S.C. $§ 154(b)(1)(B)(i)$, which states in relevant part that "if the issue of [a patent] is delayed due to the failure of the [PTO] to issue a patent

\footnotetext{
${ }^{10} \S 154(\mathrm{~b})(2)(\mathrm{C})(\mathrm{iii})$.

${ }^{11}$ Wyeth v. Kappos, 591 F.3d 1364 (Fed. Cir. 2010).

${ }^{12} \S 154(\mathrm{~b})(2)(\mathrm{A})$.

${ }^{13} 591$ F.3d at 1368 .
} 
within 3 years after the actual filing date of the application[,] not including ... any time consumed by continued examination of the application requested by the applicant [i.e., an RCE], the term of the patent shall be extended 1 day for each day after the end of that 3-year period until the patent is issued." ${ }^{14}$ The patentee argued that filing an RCE should only result in a deduction of PTA if the RCE was filed prior to the end of the three-year period following the filing date. Prior to this decision by the Federal Circuit, two district courts had so held, based on their reading of the statutory language. The Federal Circuit disagreed, however, and found that the PTO was correct in its interpretation of the statute, i.e., that the filing of an RCE results in a deduction of PTA, irrespective of whether the RCE was filed prior to or subsequent to the three-year deadline.

However, the Federal Circuit did agree with the patentee that the PTO had been acting in violation of the statute when it deducted from Type B PTA all of the time subsequent to the filing of the RCE, including the time between the notice of allowance and the date of issuance. The Federal Circuit held that, under the statute, the PTO could not deduct the time between the notice of allowance and the date of issuance, pointing out that this would be inconsistent with the fact that, when no RCE has been filed, the time between the notice of allowance and the issue date does count toward Type B delay PTA. The PTO has changed its practice, and now only deducts PTA for the days between the filing of an RCE and the notice of allowance, not patent issuance.

\section{Mohsenzadeh v. Lee}

In Mohsenzadeh v. Lee, a rare instance in which Federal Circuit decided a PTA case that did not involve a pharmaceutical patent, the court held that patents arising out of divisional applications are not eligible for PTA based on delay that occurred with respect to the parent application. ${ }^{15}$ The patentee had filed the parent application on July 6, 2001, and the PTO did not issue its first action, a restriction requirement, until September 21, 2006, more than four years after the 14-month notification period provided under $\S$ 154(b)(1)(A) had ended on September 6, 2002, resulting in a total of 1,476 days of Type A delay. The restriction requirement included four groupings of claims, each corresponding to a single invention. In response to the restriction requirement, Mohsenzadeh elected to prosecute one of the grouping, and cancelled the non-elected claims. On January 8, 2010, Mohsenzadeh filed two divisional applications from the '905 application corresponding to groups of claims identified as a separate invention in the original restric- tion requirement. Both applications issued in 2013 as patents claiming priority to the originally filed application. The PTO granted zero days of PTA for the two patents arising out of the divisional applications.

The patentee appealed the PTO's PTA determination, arguing that each patent was entitled to the 1,476 days that the PTO delayed in issuing the restriction requirement. The Federal Circuit resolved the question in favor of the PTO, finding the plain language of $\S 154(b)(1)(A)$ clearly shows that Congress intended delay in the prosecution of an application to be restored to a single patent, i.e., the patent issuing directly from that application. The term of any patent arising from a continuing application, e.g., a divisional application, is not restored for delay in the prosecution of the parent patent's application.

\section{Gilead v. Lee}

In Gilead Scis., Inc. v. Lee, the Federal Circuit held that an applicant's failure to engage in a reasonable effort to conclude prosecution constitutes applicant delay requiring a reduction in PTA, regardless of whether or not the applicant's failure actually resulted in a delay in the issuance of the patent. ${ }^{16}$ During the prosecution of the pharmaceutical patent at issue in this case, the PTO issued a restriction requirement dividing the claims in the originally filed application into four groups of inventions. The applicant responded by electing one of the groups for examination. Fifty-seven days later, prior to the PTO issuing a first office action on the merits, the applicant filed a supplemental information disclosure statement (IDS). A patent ultimately issued from the application, and in calculating its PTA the PTO deducted the 57 days, finding that it constituted a "failure to engage in reasonable effort to conclude prosecution" requiring a reduction of PTA as set forth in $\S 154(b)(2)(C)(i)$. In particular, the PTO pointed to its own regulation interpreting this provision, 37 C.F.R. $§ 1.704(\mathrm{c})(8)$, which provides in relevant part that:

Circumstances that constitute a failure of the applicant to engage in reasonable efforts to conclude processing or examination of an application... include the following circumstances[:] ... Submission of a supplemental reply or other paper, other than a supplemental reply or other paper expressly requested by the

\footnotetext{
${ }^{14}$ Novartis AG v. Lee, 740 F.3d 593 (Fed. Cir. 2014) (emphasis added).

${ }^{15}$ Mohsenzadeh v. Lee, 790 F.3d 1377 (Fed. Cir. 2015).

${ }^{16}$ Gilead Scis., Inc. v. Lee, 778 F.3d 1341 (Fed. Cir. 2015).
} 
examiner, after a reply has been filed, in which case the period of adjustment set forth in $\S$ 1.703 shall be reduced by the number of days, if any, beginning on the day after the date the initial reply was filed and ending on the date that the supplemental reply or other such paper was filed.

The patentee argued that $\S 154(b)(2)(C)(i)$, when read in context with surrounding statutory language, requires applicant behavior that results in actual delay. The patentee further pointed to the statutory purpose and legislative history in arguing that Congress intended to penalize only applicant conduct that causes actual delay. The court was not persuaded, however, finding that the legislative history of the statute did not support a conclusion that Congress aimed to distinguish between patent applicants whose "conduct attempts to delay issuance of a patent from those whose conduct actually results in a delay." The court held that the PTOs interpretation of the statute (i.e., that Congress intended to sanction not only applicant conduct that results in actual delay, but also conduct having the potential to result in delay, irrespective of whether such delay has actually occurred) was reasonable.

The court agreed with the PTO that "a supplemental reply or paper often causes delay not only in processing an examination of the particular applicant's application, but also with the processing and examination of other applications before the examiner." Thus, such conduct may have negative externalities for other patent applicants because it could result in delaying the issuance of their patents, irrespective of whether it actually results in delaying the issuance of that applicant's patent.

As the district court had noted, applicant conduct penalized under the regulation interferes with the PTO's ability to conclude the application process because of significant time constraints faced by the PTO. Because the A Delay provision of the statute penalizes the PTO if the examiner fails to respond within four months of the applicant's response to a restriction requirement, any relevant information received after an initial response to a restriction requirement interferes with the PTO's ability to process an application.

\section{Pfizer v. Lee}

In Pfizer, Inc. v. Lee, the Federal Circuit held that the PTO can stop the accrual of Type A delay by issuing an incomplete restriction requirement. ${ }^{17}$ The relevant pharmaceutical patent application was filed on May 2, 2003, and the PTO mailed a restriction requirement on August 10, 2005, 404 days after the expiration of the 14-month statutory deadline. On February 6, 2006, the applicant participated in a telephone interview with the examiner and explained that some of the originally filed claims had been omitted from the restriction requirement. During the interview, the examiner acknowledged that the restriction requirement was not complete; he agreed to withdraw it and subsequently issued a corrected restriction requirement on February 23, 2006 (601 days after the statutory deadline). When a patent ultimately issued on April 10, 2012, the PTO did not award A Delay for the 197 days that elapsed between the mailing of the first restriction requirement and the corrected restriction requirement.

The patentee appealed the PTO's determination not to award PTA for the 197 days, arguing that (1) the PTO's original restriction requirement failed to satisfy the notice requirement of $\S 132$ because it failed to classify six dependent claims into the examiner's defined invention groups, and thus failed to place the applicants on notice of the restriction requirement as to those dependent claims; (2) the initial restriction requirement was not valid because the examiner had treated it as though it had "been withdrawn"; and (3) the initial restriction requirement should accordingly be treated as a "non-event" for purposes of determining whether $\S 132$ was satisfied, and, hence, whether Type A delay should have ceased accruing under the Act.

The court disagreed, and affirmed the PTO's determination of PTA. The court found that the examiner's initial restriction requirement satisfied the statutory notice requirement because it clearly defined the invention groups available for election and further prosecution, thus placing applicants on sufficient notice of the reasons for the examiner's restriction requirement. As for the six claims whose classifications were omitted from the initial restriction requirement, the court found that the applicant could have taken direction for their classification from the fact that their respective independent claims were each included in the initial restriction requirement. The court found that the applicants' and examiner's exchanges concerning the challenged restriction requirement were part of the typical "back and forth" process of patent prosecution. The court emphasized that the underlying purpose of PTA is to compensate patent applicants for certain reductions in patent term that are not the fault of the applicant, not to guarantee the correctness of the agency's every decision, and concluded that the examiner's error that occurred in this case is not the type for

\footnotetext{
${ }^{17}$ Pfizer, Inc. v. Lee, 811 F.3d 466 (Fed. Cir. 2016).
} 
which the PTA provisions of the Patent Act were intended to compensate.

\section{Supernus v. Iancu}

In Supernus Pharm., Inc. v. Iancu, the Federal Circuit held that, under a plain reading of the statute, any reduction in PTA for applicant delay may not exceed the "time during which the applicant failed to engage in reasonable efforts to conclude prosecution of the application." ${ }^{18}$ The PTO had, with respect to the pharmaceutical patent at issue in the case, exceeded its discretion in interpreting the statute in a manner that resulted in a reduction in PTA for inactivity during a period of time in which the PTO had failed to show that there was anything the applicant could have done to speed the issuance of the patent.

The PTO regulation at issue in Supernus was the same as in Gilead, § 1.704(c)(8), which regulates the calculation for reduction of PTA in instances where the applicant submits a supplemental paper to the USPTO. Recall that $\S 1.704(\mathrm{c})(8)$ provides:

Submission of a supplemental reply or other paper, other than a supplemental reply or other paper expressly requested by the examiner, after a reply has been filed, in which case the period of adjustment set forth in $\S$ 1.703 [that extends the patent's term due to USPTO delay] shall be reduced by the number of days, if any, beginning on the day after the date the initial reply was filed and ending on the date that the supplemental reply or other such paper was filed ....

As was the case in Gilead, the disputed deduction of PTA was prompted by the filing of a supplemental IDS, in this case subsequent to an RCE filed by Supernus on February 22, 2011. A year and half after the filing of the RCE, on August 21, 2012, the European Patent Office (EPO) notified Supernus's European patent counsel that a Notice of Opposition citing 10 documents had been filed by Sandoz AG to an EP patent claiming priority from Supernus's pending U.S. application. Several weeks later, on September 11, 2012, Supernus received a letter from its European patent counsel disclosing the EPO notification and the Opposition. On November 29, 2012, 100 days after the EPO notification of the Opposition, Supernus submitted a supplement IDS to the PTO informing the agency of the Opposition and providing the cited documents. Patent applicants are required to submit to the PTO communications such as this from foreign patent offices that address the patentability of a related patent application. An applicant's failure to do so could easily result in an allegation of inequitable conduct, and the PTO actively encourages such submissions. Of particular relevance to this case, when an applicant submits an IDS disclosing a communication from a foreign patent office, PTO regulations provide a 30-day safe harbor that exempts any reduction of PTA under $\S 1.704(\mathrm{c})(8)$, provided that the IDS is submitted within 30 days of the applicant receiving the information from the foreign patent office that is eventually contained in the IDS. ${ }^{19}$ Supernus failed to qualify for the safe harbor, however, by failing to file the supplemental IDS within 30 days of the EPO notice.

On June 10, 2014, the PTO issued a patent reflecting a PTA of 1,260 days, which the PTA arrived at after deducting 886 days attributed to applicant delay, including 646 days assessed for the period between the February 22, 2011 filing of the RCE and the November 29, 2012 submission of the IDS. Supernus requested PTO reconsideration of this 646-day reduction in the PTA, but the request was rejected. The PTO determined that under Gilead, submission of an IDS after the filing of a response to an election or restriction requirement is subject to a reduction under 37 C.F.R. $\S 1.704(\mathrm{c})(8)$ because any relevant information submitted to the PTO after an initial reply interferes with the PTO's ability to process an application. The PTO found that the same analysis applies to submission of an IDS document after the filing of an RCE because any IDS submission by a patentee after the filing of an RCE interferes with the PTO's ability to process an application because the examiner may be forced to go back and review the application again. The PTO concluded that 37 C.F.R. $\S 1.704(c)(8)$ applies in this case, and that the reduction of the PTA by the 646 days due to applicant delay was proper.

Supernus appealed to the U.S. District Court for the Eastern District of Virginia, arguing that 37 C.F.R. $\S 1.704(c)(8)$ is arbitrary, capricious, and contrary to the PTA statute, and that of the 646-day period that the USPTO attributed to applicant delay, it was entitled to at least 546 of those days-i.e., the period between its filing of the RCE and the EPO notification of the Sandoz Opposition.

The district court granted summary judgment in favor of the PTO, upholding § 1.704(c)(8) and concluding that the PTO did not err in the PTA calculation for the ' 897 patent. The court believed that the Federal Circuit's decision in Gilead foreclosed, as a

\footnotetext{
${ }^{18}$ Supernus Pharm., Inc. v. Iancu, 913 F.3d 1351 (Fed. Cir. 2019).

${ }^{19} 37$ C.F.R. $\S 1.704(\mathrm{~d})(1)$.
} 
matter of law, Supernus's statutory interpretation arguments that $\S 1.704(\mathrm{c})(8)$ is arbitrary, capricious, and otherwise contrary to the PTA statute.

On appeal, the Federal Circuit reversed, concluding that Gilead did not foreclose Supernus's statutory interpretation argument, because a different aspect of the regulation was at issue in that case. Gilead ruled only that the regulation reasonably drew no line between actual and potential delay and could include a supplemental IDS, but never considered the question at issue in Supernus, i.e., whether the PTO could deduct PTA for purported applicant delay during a period of time in which there was no failure to engage in reasonable efforts to conclude prosecution.

The Federal Circuit applied the Chevron framework to analyze the PTO's interpretation of the statute and found that, at the first step of the Chevron analysis, the statute answered the precise question at issue in the case, i.e., whether the PTO may reduce PTA by a period that exceeds the "time during which the applicant failed to engage in reasonable efforts to conclude prosecution." Section 154(b)(2)(C)(i), on its face, requires that any PTA reduction be equal to the period of time during which an applicant fails to engage in reasonable efforts.

The court agreed with Supernus that there were no efforts that it could have taken during the 546 days preceding the EPO's notice of Opposition, noting that the record was silent as to what Supernus could have done to conclude prosecution during the 546day time period, beginning with the filing of the RCE/IDS on February 22, 2011, and ending on the date of the EPO notification, August 21, 2012. To the contrary, the facts indicate that there was no action Supernus could have taken to advance prosecution of the patent during the 546-day period, particularly because the EPO notice of opposition did not yet exist. The court found that the PTO's interpretation of the statute unfairly penalized applicants, did nothing to incentivize applicants not to delay, and failed to protect applicants' full patent terms.

\section{Mayo v. Iancu}

In Mayo Found. for Med. Educ. \& Research $v$. Iancu, the court sided with the PTO's decision to deduct PTA for delay for time that elapsed between the termination of an interference and notice of allowance, because an RCE was filed prior to declaration of the interference. ${ }^{20}$ During prosecution of the patent, the applicant, facing final rejection based on the examiner's assertion that the claims were anticipated by a prior art patent, responded by filing an RCE on September 14, 2011, along with remarks arguing that the applicant had priority of invention over the prior art patent, and suggesting that the PTO declare an interference between the pending claims and the prior art patent. About five months later, on February 9, 2012, an interference was declared between the pending claims of the application and all the claims of the prior art patent. The interference proceeded for two years. On February 19, 2014, the Board awarded priority to the application claims and cancelled all the claims of the patent. The interference decision became final on April 23, 2014, when the 60-day period for appeal expired.

Following termination of the interference, the application was returned to the examiner, who conducted a further prior art search, and on June 30, 2014, issued an Office action rejecting the claims on the ground of non-statutory obviousness-type double patenting. The applicant filed a reply that persuaded the examiner to withdraw the rejection, and a notice of allowance was mailed on November 3, 2014.

The PTO calculated a PTA for the patent of 621 days, which included a deduction for 342 days of RCE time that resulted in an award of no Type B delay: 148 days for the time between the filing of the RCE and the declaration of the interference, and 194 days for the time between the termination of the interference and mailing of the notice of allowance. No time was deducted for the period corresponding to the interference, which is clearly a form of Type C delay, as discussed above. The patentee appealed, arguing that only the 148 days between the filing of the RCE and the declaration of interference should be deducted from PTA. The patentee argued that " $[t]$ he examiner's sua sponte reopening of prosecution after termination of the interference was not [RCE time under 35 U.S.C. § 154(b)(1)(B)(i)].” The applicant argued that it never "requested" any examination after the Board's remand and that, under PTO regulations, an interference cannot be declared unless at least some claims, and in this case all of the claims, are deemed allowable but for the outcome of the interference. It further argued that, under Novartis $A G v$. Lee, RCE time ends "once the [PTO] takes an official action indicating that all the pending claims are allowable and closes prosecution," or the claims are "deemed allowable."

The Federal Circuit rejected these arguments, pointing out that while the PTO's regulations do indicate that at least one claim in an application

${ }^{20}$ Mayo Found. for Med. Educ. \& Research v. Iancu, 938 F.3d 1343 (Fed. Cir. 2019). 
should be in condition for allowance before an interference is declared, they also explicitly contemplate that the Board may recommend further action by the examiner, including issuing a rejection. Thus, the PTO's regulations as a whole do not indicate that a declaration of an interference is tantamount to a notice of allowance. The court further noted that while the filing of an RCE entitles an applicant to continue examination, the examiner is allowed to issue a new ground of rejection, just as is the case during regular examination.

The court was also persuaded by the PTO's argument that to side with the applicant in this case could result in requiring the agency to conduct an "unduly burdensome, fact-intensive inquiry into whenever the PTO actually conceded the allowability of the claims." For example, in this case the applicant claimed that, after it filed its RCE, the examiner "indicated" on a phone call that its claims were in condition for allowance but for the interference (or, in the words of the applicant, the claims were "deemed allowable"). The court found that it was understandable that the PTO would wish to avoid such disputes over what "indicated" means, and when claims are "deemed allowable."

\section{Intra-Cellular Therapies v. Iancu}

In Intra-Cellular Therapies, Inc. v. Iancu, the Federal Circuit affirmed the PTO's determination that a response to a final Office action that continues to argue the merits of an examiner's final rejection constitutes a "failure to engage in reasonable efforts to conclude prosecution," and will not stop the accrual of applicant delay resulting in a deduction of PTA. ${ }^{21}$ During prosecution of the relevant patent application, the PTO issued a final Office action rejecting some claims and objecting to the others. On the three-month deadline for responding to the final Office action without beginning to accrue applicant delay resulting in deduction of PTA, the applicant filed its first response. This initial response continued to argue the merits of the examiner's final rejections. The examiner was not persuaded, and so 21 days after filing the first, unsuccessful response (which was 21 days after the three months allotted under the PTA statute), the applicant filed a second response, this time completely capitulating to all of the examiner's rulings by canceling or amending every rejected or objected to claim based on the examiner's positions, which resulted in a notice of allowance.

In calculating PTA for the resulting patent, the PTO determined that the extra 21 days it took the applicant to file a successful response after the threemonth deadline for responding to the final Office action constituted applicant delay, resulting in a 21day deduction. The pertinent PTO regulation, 37 C.F.R. $§ 1.704(b)$, provides that "an applicant shall be deemed to have failed to engage in reasonable efforts to conclude processing or examination of an application for the cumulative total of any periods of time in excess of three months that are taken to reply to any notice or action by the [Patent] Office making any rejection, objection, argument, or other request," which closely tracks the language of $\S$ 154(b)(2)(C)(ii). The applicant argued that its first response was a "reply" that should have stopped the accrual of applicant delay time, since it addressed all of the grounds of rejection and objection made by the examiner in the final rejection and was a bona fide attempt to advance prosecution.

It is certainly the case that under PTO regulations a response to a non-final Office action that addresses each and every outstanding objection and rejection does constitute a "bona fide attempt to advance prosecution," a thus a "reply" for purposes of calculating PTA. ${ }^{22}$ But the situation is different when it comes to a "final" office action, which marks the end of normal prosecution as of right. ${ }^{23}$ Under PTO regulations, the patent examiner is not obligated to engage in further examination and review of the patent application or applicant arguments after entering a final rejection, and the applicant only has a limited number of options to pursue. In order to constitute a response that will necessarily stop accrual of applicant delay, the applicant must either file an RCE or appeal and/ or cancel rejected claims.

On appeal, the Federal Circuit applied the Chevron framework to analyze whether the PTO's interpretation of the statute was permissible. At Step 1 of the analysis, the court found that the plain language of the statute did not answer the precise question at issue, which is "whether an applicant submission, filed after a final Office action, that continues to argue the merits of the examiner's rejection, without good cause, constitutes a "fail[ure] to engage in reasonable efforts to conclude prosecution" such that applicant delay would accrue under the PTA statute. The court then proceeded to Step 2, and found that

\footnotetext{
${ }^{21}$ Intra-Cellular Therapies, Inc. v. Iancu, 938 F.3d 1371 (Fed. Cir. 2019).

${ }^{22} \S 1.135 ; \S 1.111$.

${ }^{23}$ See 37 C.F.R. § 1.113(a), (c); § 1.114(b) ("Prosecution in an application is closed as used in this section means ... that the last Office action is a final action ...."); MPEP $§ 714.12$ ("Once a final rejection that is not premature has been entered in an application, applicant or patent owner no longer has any right to unrestricted further prosecution.").
} 
the PTO's answer to the question was based on a "permissible construction of the statute." Thus, the court held that it is permissible to interpret an after-final submission that continues to argue the merits of an examiner's final rejection as a "failure to engage in reasonable efforts to conclude prosecution" such that such an applicant submission would not stop the accrual of applicant delay under the PTA statute.

The court found that the PTO's determination as to what constitutes an appropriate reply to a final office action was consistent with pre-existing regulatory requirements set forth in $\S 1.113$ for responding to a final Office action, and that these pre-existing regulatory requirements had not been challenged.

Because the applicant's second after-final submission amended the application to conform with all the requirements the examiner had set forth in the Advisory Action, the Patent Office effectively determined that this response constituted "reasonable efforts to conclude prosecution," cutting off any further accrual of applicant delay.

The applicant's proposed interpretation of "reply" under $\S 1.704(b)$ as any bona fide attempt to address all rejections and objections in an Office action was found to be impermissible because it incorrectly applies the standard for a compliant "reply" to a non-final Office action. The court pointed out that under this interpretation:

an applicant would be allowed to continue to liberally argue and make amendments without accruing applicant delay as long as it addressed all outstanding issues in the final Office action. But treating this type of submission as a proper "reply" would give the applicant the benefits of an RCE (which re-opens prosecution) without the concomitant PTA reduction that comes with an RCE. This clearly contravenes the structure of the existing PTA statute, which prevents extension of PTA through B Delay accrual for time consumed by an RCE. ${ }^{24}$

\section{Idorsia v. Iancu}

Idorsia Pharm., Ltd. v. Iancu, is the most recent Federal Circuit decision to address PTA, and the issue in the case was very similar to that in Pfizer, i.e., the effect of the PTO's filing of an erroneous restriction requirement on PTA. ${ }^{25}$ As was the case in Pfizer, the Federal Circuit concluded that the time between the filing of an erroneous restriction requirement and a corrected restriction requirement does not constitute Type A delay, and will not count towards PTA for the patent that issues, even though the lag be- tween the filing of the erroneous and corrected restriction requirement presumably can result in a delayed issuance of the patent and a resulting reduction in patent term.

The patent application as filed included claims directed towards a large group of structurally related chemical compounds. On March 14, 2012, the PTO examiner issued a restriction requirement identifying six independent and distinct inventions. In response, the applicant notified the examiner by telephone that the examiner's defined invention groups omitted certain subject matter from the scope of the claims. The examiner agreed and indicated that he would issue a new restriction requirement. Significantly, the applicant did not elect any of the invention groups in the initial restriction requirement, instead choosing to wait for the corrected restriction requirement.

About one month later, on April 18, 2012, the examiner issued a second restriction requirement that superseded and replaced the first restriction requirement. This second restriction requirement was also issued in error, omitting certain subject matter claimed in the original claims, and once again the applicant chose not to respond. The examiner subsequently issued a third restriction requirement on June 21, 2012, which divided all pending claims into three distinct invention groups. The applicant filed a response to the third restriction requirement, electing one of the three invention groups identified by the examiner, and traversed the restriction.

When the PTO determined PTA for the patent that ultimately issued, it did so based on its conclusion that Type A delay stopped accruing after the examiner's first restriction requirement. The applicant challenged the PTO's PTA determination in district court under the Administrative Procedure Act (APA), arguing that Type A delay continued to accrue for an additional 99 days after the date calculated by the PTO because the first and second restriction requirements did not meet the notice requirement of 35 U.S.C. $\S 132$. The district court granted summary judgment in favor of the PTO, holding that the first restriction requirement complied with $\S 132$ based on the standard set forth in Pfizer, and on appeal the Federal Circuit affirmed.

The Federal Circuit noted that Pfizer had held that $\S 132$ merely requires that an applicant at least be informed of the broad statutory basis for the rejection of his claims, so that he may determine

\footnotetext{
${ }^{24} I d$. at 1382.

${ }^{25}$ Idorsia Pharm., Ltd. v. Iancu, No. 2019-2346, 2020 WL 2312344 (Fed. Cir. May 11, 2020).
} 
what the issues are on which he can or should produce evidence. In this case, the examiner's first restriction requirement asserted that all pending claims of the ' 358 application were subject to the restriction requirement. The first restriction requirement also defined the invention groups available for election, and articulated the reasons that the examiner believed that the ' 358 application claimed multiple distinct inventions. The court noted:

[The applicant] was able to respond to the first restriction requirement and successfully oppose the examiner's description of the multiple invention groups, which demonstrates that [the applicant] was able to understand the examiner's proposed invention groups and prepare responsive arguments. Thus, as in Pfizer, the first restriction requirement, when viewed as a whole, provided adequate grounds on which [the applicant] could recognize and seek to counter the grounds for rejection. ${ }^{26}$

The Federal Circuit held that a "restriction requirement need not be correct to satisfy the statutory notice requirement," and that the applicant's and the examiner's exchanges concerning the challenged restriction requirement were part of the typical "back and forth" process of patent prosecution.

Although this process often involves changes in both the applicant's and examiner's positions, an examiner's reissuance of an office action in response to an applicant's suggestion does not automatically mean that an application has been "delayed" for purposes of patent term adjustment. Section 132 does not award additional A delay if an applicant successfully convinces the PTO that the Office action was erroneous. Indeed, the underlying purpose of PTA is to compensate patent applicants for certain reductions in patent term that are not the fault of the applicant, not to guarantee the correctness of the agency's every decision. Based on the record evidence, we agree with the PTO and the district court that Idorsia's alleged delay is not the type of error for which the Act was intended to compensate. ${ }^{27}$

\section{PTO NOTICES RESPONDING TO SUPERNUS}

May 9, 2019 notice

On May 9, 2019, six months after it was decided, the PTO issued a notice in the Federal Register entitled Patent Term Adjustment Procedures in View of the Federal Circuit Decision in Supernus Pharm., Inc. v. Iancu. ${ }^{28}$ In this notice, the PTO pointed out that its PTA determinations are performed by a computer program that uses information recorded in the PTO's PALM system relating to the communications exchanged between applicant's and the PTO during the patent application process. The event from which the Federal Circuit measured the beginning of the patent term adjustment reduction in Supernus, i.e., the EPO's notice of the opposition that had been filed with respect to the related EP patent, is an event that is external to the PTO and thus not an event that is recorded in the PALM system. Thus, under current practices, it would be impossible for the PTO to automatically take such an event into account when calculating PTA.

Instead of altering its PTA calculation practice, which would no doubt be very difficult, the notice states that the PTO would continue to determine PTA based upon the beginning and ending dates of events recorded in the PALM system. It goes on, however, to explain that a patentee dissatisfied with a PTA determination may file a request for reconsideration, stating the patentee's belief that the period of PTA reduction for applicant delay calculated by the PTO exceeds the period of time during which the patentee failed to engage in reasonable efforts to conclude prosecution of the application, because there was no identifiable effort the patentee could have undertaken to conclude prosecution of the underlying application. The notice states that such a request for reconsideration must provide any relevant information which is not recorded in the PALM system, including factual support, to show that there was no identifiable effort the patentee could have undertaken to conclude the prosecution of the underlying application during a portion of the period of time which was treated as applicant delay under 37 C.F.R. $§ 1.704(c)$. "For example, in a situation analogous to Supernus, the request for reconsideration must include the facts concerning how and when each of the documents contained in the information disclosure statement at issue were first cited by the [PTO] or a foreign authority in a related or counterpart application."

In the notice, the PTO states that it expects that situations of the type that occurred in Supernus will, in the future, only arise infrequently. "An extended delay between the filing of a request for continued examination and the subsequent office action

\footnotetext{
${ }^{26} I d$. at $* 3$ (citations omitted).

${ }^{27} \mathrm{Id}$.

${ }^{28} 84$ Fed. Reg. 20343 (May 9, 2019).
} 
(932 days in Supernus) should be a rare occurrence now as the average time between the filing of a request for continued examination and the subsequent Office action is currently only 79 days."

\section{June 16, 2020 notice}

On June 16, 2020, the PTO issued a final rule notice entitled Patent Term Adjustment Reductions in View of the Federal Circuit Decision in Supernus Pharm., Inc. v. Iancu. ${ }^{29}$ In particular, the final rule revises several of the provisions in 37 C.F.R. § 1.704. Section 1.704 sets forth a list of exemplary circumstances that the PTO has determined to constitute a failure of the applicant to engage in reasonable efforts to conclude processing or examination of a patent application under 35 U.S.C. $\S 154(b)$. In particular, 37 C.F.R. § 1.704(c)(2), (3), (6), (9), and (10) are revised under the final rule. The provision that was specifically at issue in Supernus, 37 C.F.R. $§ 1.704(c)(8)$, was not revised, presumably because the PTO concluded that it was the agency's application of the provision in that case, rather than the language of the provision itself, which violated the plain meaning of the statute. Instead, as explained in the May 9 notice, the PTO will continue to calculate PTA deductions pursuant to $\S 1.704(c)$ (8) as they have always done, using the PALM system, and leave it to patent applicants to petition for reconsideration if the sort of situation that occurred in Supernus occurs again.

The PTO has presumably concluded that it would not be reasonable for the agency to attempt to develop mechanisms by which the agency would be alerted of notices filed by foreign patent agencies that would trigger a U.S. applicant's duty to submit a supplemental IDS, such as the notice of opposition issued by the EPO in Supernus. Better to put the onus on patent applicants to bring such an event to the PTO's attention. As noted in the May 9 notice, the PTO hopes that in the future such occurrences will be rare, due to the much faster processing time the PTO is now achieving compared to during the relevant time frame in Supernus. This seems reasonable to me, particularly since a patent applicant can avoid the issue altogether by simply exercising diligence and submitting a supplemental IDS within the 30 days allowed under 37 C.F.R. $\S 1.704(\mathrm{~d})(1)$, in which case the filing of the supplemental IDS will not result in any deduction from PTA.

The notice accompanying the final rule states that $\S 1.704(c)(2),(3),(6),(9)$, and (10) were in violation of the holding of Supernus because the period of reduction specified in these provisions corresponds to or includes consequences to the PTO of the appli- cant's failure to engage in reasonable efforts to conclude prosecution, rather than "the period from the beginning to the end of the applicant's failure to engage in reasonable efforts to conclude prosecution," as required by the plain language of the statute. In other words, prior to Supernus the PTO was penalizing patentees for all of the delay that occurred in the processing an application, including delay that could have been shortened if the PTO had acted more diligently, as well as delay that the applicant was in no position to do anything about.

In Supernus, for example, the PTO was required by statute to respond to the applicant's RCE within four months to avoid accrual of PTA to compensate the applicant for the PTO's lack of diligence. Not only did the PTO fail to respond within the allotted four months, it had yet to respond more than a year after the four months had expired, when the EPO issued its notice of the opposition 546 days after the RCE was filed. When calculating PTA, the PTO deducted this entire 546 days from the patent term, even though the 546 days of nonresponse to the RCE was a consequence of the PTO's failure to act in a diligent manner, and there was nothing the applicant could have done to speed the process. Not only is this grossly unfair, but it clearly exceeds the language of the statute. Of course, the PTO's response would be that if the applicant had simply filed it supplemental IDS within 30 days of receiving notice from the EPO it could have benefited from the safe harbor and avoided the 546-day penalty. But the penalty imposed by the PTO, 546 days deducted from the patent term, seems quite excessive. Under the correct interpretation of the statute, as set forth in Supernus, the applicant was still penalized for missing the 30-day deadline, but only the 100 days that elapsed between the EPO communication and the filing of the supplemental IDS, not 646 days as initially calculated by the PTO.

Section 1.704(c)(2) provides for a deduction of PTA when the patent applicant files a request for deferral of issuance of the patent. Under the provision prior to the final rule, the PTA was reduced by the number of days beginning on the date of the request for deferral and ending on the date of the patent issued. This pre-final rule deduction includes the time between the applicant's filing of a request to terminate the deferral and the issuance of the patent, a period of time during which the applicant has done all it can to hasten the issuance of the patent, putting the ball squarely in the court of the PTO. Thus,

${ }^{29} 85$ Fed. Reg. 36335 (June 16, 2020). 
under this pre-final rule provision, the longer the PTO delayed in issuing the patent after the request to terminate deferral, the shorter the patent term, punishing the patentee for delay on the part of the PTO that the applicant could not control. To bring this provision into compliance with the statute and Supernus, the final rule revises the provision such that the period of reduction of PTA begins with the date on which deferral is requested and ends on the date on which the applicant files a request to terminate the deferral (or on the date the patent issued if that occurs earlier).

Section 1.704(c)(3) provides for a deduction of PTA when the applicant abandons the patent application or is late in paying the issue fee. Prior to the final rule, the provision provided for a reduction in PTA corresponding to the number of days beginning on the date of abandonment, or the day after the date the issue fee was due, and ending the date the PTO mailed the decision reviving the application or accepting the late payment of the issue fee. The provision violated Supernus because it penalized the patentee for the period of time that elapsed between the applicant's filing of a petition to revive the application (or to accept late payment of the issue fee) and the day on which the PTO granted the petition by reviving the application or accepting the late payment. The final rule addresses this problem by revising this provision such that the period of PTA reduction corresponds to the number of days beginning on the date of abandonment and ending on the date in which the applicant filed a grantable petition to revive the application (or beginning the day after the date the issue fee was due and ending on the date the grantable petition to accept late payment was filed).

Section 1.704(c)(6) provides for a deduction of PTA when the applicant submits a preliminary paper (e.g., a preliminary amendment) less than one month before the filing of an Office action or notice of allowance and that submission requires the PTO to mail a supplemental Office action or notice of allowance. Under the pre-final rule provision, a reduction of PTA was imposed corresponding to the number of days beginning on the day after the mailing date of the original office action or notice of allowance and ending on the date of mailing of the supplemental office action or notice of allowance (for a maximum reduction of four months). Once again, this version of the provision penalized the applicant for delay on the part of the PTO over which the applicant had no control. The final rule revised the provision such that now the reduction corresponds to the number of days beginning on the day after the date that is eight months after the application's filing date and ending on the date the preliminary paper was filed. This eight-month period corresponds to the eight-month period for placing an application in condition for examination, as set forth in $\S$ rule $1.704(\mathrm{c})(13))^{30}$ Thus, under the final rule's revision of $\S 1.704$ (c)(6), an applicant will not be penalized for filing a preliminary amendment, or other preliminary paper, so long as it is filed within eight months of the filing date, regardless of whether it results in the PTO having to file a supplemental office action or notice of allowance. This seems reasonable. So long as the preliminary paper is filed within eight months of the filing date, the PTO will have at least six additional months to file any supplemental office action or notice of allowance necessitated by the preliminary paper, while still meeting the 14-month deadline and thus avoiding Type A delay.

Section 1.704(c)(9) provides for a deduction of PTA when the applicant submits a paper (e.g., an amendment) after a decision by the PTAB or a federal court less than one month before the mailing of an office action or notice of allowance, and the submission of the paper requires the PTO to mail a supplemental office action or supplemental notice of allowance. Under the pre-final rule provision, the deduction of PTA would correspond to the period of time between the mailing date of the original office action or notice of allowance and the mailing date of the supplemental office action or notice of allowance. Once again, the patentee was penalized for delay by the PTO during a period of time in which there was no action the applicant could take to speed the issuance of the patent. Under the final rule, the provision has been revised such that the reduction of PTA corresponds to the number of days elapsed in between the PTAB (or federal court) decision and the filing of the paper, which the applicant has control over.

Section 1.704(c)(10) provides for a deduction of PTA when the applicant submits an amendment after a notice of allowance has been given. Under the pre-final rule version of the provision, the patentee was penalized by deduction in PTA corresponding to the number of days between the date the amendment was filed and ending on the mailing date of the office action or notice in response to the amendment. Again, the provision violated Supernus and the statute by penalizing the patentee

\footnotetext{
${ }^{30}$ See Changes to Implement the Patent Law Treaty, 78 Fed. Reg. 62367, 62385 (Oct. 21, 2013) (application is expected to be in condition for examination no later than eight months from its filing date (or date of commencement of the national stage in an international application)).
} 
for delay that occurred when the ball was in the PTO's court, and there was nothing the applicant could do to speed up issuance of the patent. The final rule revised the provision, such that the period of deduction is now calculated based on the time that elapses between the mailing of the notice of allowance and the date the amendment (or other paper) was filed.

Finally, § 1.704(c)(10) was also revised under the final rule to exclude "an amendment under $\S 1.312$ or other paper expressly requested by" the PTO from amendments or other papers filed after a notice of allowance that will result in a reduction of PTA. Only a "voluntary" amendment after a notice of allowance, i.e., an amendment not expressly requested by the PTO, will trigger a reduction in PTA. The notice of the final rule warns that an amendment going beyond what was requested by the PTO (i.e., including material not expressly requested by the PTO in addition to what was requested) will be treated as voluntary for purposes of $\S 1.704(c)(10)$.

\section{CONCLUDING THOUGHTS}

The Federal Circuit has found on a number of occasions that the PTO's interpretation and implementation of certain provisions of 35 U.S.C. $\S 154(\mathrm{~b})$ pertaining to the calculation of PTA is contrary to the clear language of the statute, and has required the agency to revise its practices to comply with the statute. ${ }^{31}$ On the other hand, in cases where the language of the statute leaves room for interpretation, the court has generally deferred to the agency. ${ }^{32}$

In Pfizer and Idorsia, the Federal Circuit made clear that the PTA provisions of the statute do not provide compensation for all actions by the PTO that can lead to a delay in patent issuance. In both those cases, the examiner issued defective restriction requirements, which delayed prosecution, but the court held that under the statute the PTO's error did not constitute compensable Type A delay. In essence, the statute only requires the PTO to take action in a timely manner, it provides no remedy in cases in which the PTO's action is timely but erroneous.

And in Mohsenzadeh, we saw that the statute only provides PTA for the delayed issuance of a restriction requirement with respect to a single application, not for patents arising out of divisional applications necessitated by the restriction requirement. In order to avoid this sort of loss of patent term for patents arising out of divisional applications, a patent applicant would need to file multiple patent applications in anticipation of the restriction requirement. For example, if Mohsenzadeh had filed four applications initially, as opposed to waiting and filing divisional applications years later, those four non-continuing applications would have all been eligible for PTA arising out of the PTO's delayed action on the applications.

\footnotetext{
${ }^{31}$ See, e.g., Wyeth v. Kappos, 591 F.3d 1364 (Fed. Cir. 2010) (PTO improperly used either the greater of the A delay or B delay to determine the appropriate PTA but never combined the two, contrary to plain directive of statute); Novartis $A G$ v. Lee, 740 F.3d 593 (Fed. Cir. 2014) (PTO violated plain reading of the statute by deducting from Type B PTA all of the time subsequent to the filing of the request for continued examination (RCE), including the time between the notice of allowance and the date of issuance); Supernus Pharm., Inc. v. Iancu, 913 F.3d 1351 (Fed. Cir. 2019) (PTO violated plain reading of the statute by reducing PTA for applicant delay by an amount exceeding the "time during which the applicant failed to engage in reasonable efforts to conclude prosecution of the application").

${ }^{32}$ See, e.g., Novartis AG v. Lee, 740 F.3d 593 (Fed. Cir. 2014)(PTO's determination that the filing of an RCE prior to the three year deadline for Type B delay results in a deduction of PTA was upheld); Intra-Cellular Therapies, Inc. v. Iancu, 938 F.3d 1371 (Fed. Cir. 2019) (PTO's determination that a response to a final Office action that continues to argue the merits of an examiner's final rejection will not stop the accrual of applicant delay resulting in a deduction of PTA was based on a "permissible construction of the statute").
} 